\title{
TGF- $\beta$ LAP Degradation Products, a Novel Biomarker and Promising Therapeutic Target for Liver Fibrogenesis
}

\author{
Mitsuko Hara, Tomokazu Matsuura, and Soichi Kojima
}

\begin{abstract}
While there are many blood and/or tissue biomarkers as well as algorithms clinically used to assess hepatic fibrosis, a good biomarker and therapeutic target of hepatic fibrogenesis, which reflects prefibrotic changes, has not been established. The most fibrogenic cytokine, transforming growth factor (TGF)- $\beta$, is produced as a latent complex, in which TGF- $\beta$ is trapped by its propeptide. On the surface of activated hepatic stellate cells, plasma kallikrein activates TGF- $\beta$ by cleaving latency-associated protein (LAP) between the $\mathrm{R}^{58}$ and $\mathrm{L}^{59}$ residues, releasing active TGF- $\beta$ from the complex. We made specific antibodies that recognize neo-C-terminal $\left(\mathrm{R}^{58}\right)$ and N-terminal $\left(\mathrm{L}^{59}\right)$ ends of LAP degradation products (LAP-DPs) and found that LAP-DPs may serve as a novel surrogate marker of TGF- $\beta$ activation - namely, generation of active TGF- $\beta$ - and is thus a therapeutic marker for TGF- $\beta$-mediated liver fibrogenesis in patients and can also be used to monitor effects of anti-fibrogenic factors or compounds for discovery of a novel anti-fibrosis drug.
\end{abstract}

Keywords Biomarkers • Hepatic fibrogenesis $\bullet$ TGF- $\beta \bullet$ LAP $\bullet$ Latent TGF- $\beta$ activation $\bullet$ Hepatic stellate cells $\bullet$ Plasma kallikrein $\bullet$ LAP-DP $\bullet$ Drug discovery $\bullet$ Anti-fibrosis drug

\section{Abbreviations}

ECM Extracellular matrix

HSCs Hepatic stellate cells

$\alpha$ SMA $\quad \alpha$ smooth muscle actin

TGF- $\beta 1 \quad$ Transforming growth factor- $\beta 1$

M. Hara • S. Kojima, Ph.D. ( $\varangle)$

Micro-Signaling Regulation Technology Unit, RIKEN Center for Life Science Technologies,

2-1 Hirosawa, Wako, Saitama 351-0918, Japan

e-mail: m-hara@riken.jp; skojima@riken.jp

T. Matsuura

Department of Laboratory Medicine, The Jikei University School of Medicine,

Minato-ku, Tokyo 105-0003, Japan

e-mail: matsuurat@jikei.ac.jp

K. Nakao et al. (eds.), Innovative Medicine, DOI 10.1007/978-4-431-55651-0_26 


$\begin{array}{ll}\text { LAP } & \text { Latency associated protein } \\ \text { SLC } & \text { Small latent complex } \\ \text { LTBP } & \text { Latent TGF- } \beta \text { binding protein } \\ \text { LLC } & \text { Large latent complex } \\ \text { PLN } & \text { Plasmin } \\ \text { PLK } & \text { Plasma kallikrein } \\ \text { LAP-DP } & \text { LAP degradation products } \\ \text { LAP } \beta 1 & \text { TGF- } \beta 1 \text { LAP } \\ \text { BDL } & \text { Bile duct ligation } \\ \text { HBV } & \text { Hepatitis B virus } \\ \text { HCV } & \text { Hepatitis C virus } \\ \text { NASH } & \text { Non-alcoholic steatohepatitis }\end{array}$

\section{Introduction of Liver Fibrogenesis}

Hepatic fibrosis is the excessive accumulation of extracellular matrices (ECM; mainly collagen) in the perisinusoidal space (or space of Disse) in the liver, and an important pathological step developing from chronic hepatitis to liver cirrhosis irrespective of etiologies [1], whereas hepatic fibrogenesis means fibrosis progression or an ongoing reaction producing excessive ECM, sometimes nonsymptomatic, in the liver [2]. While there are many blood and/or tissue biomarkers as well as algorithms clinically used to assess hepatic fibrosis [3-7], the gold standard is still scoring of stained collagen fibers in the biopsy sample [3]. However, biopsy is invasive and risky. Imaging techniques including ultrasound elastography have been developed [3]. In contrast, a good biomarker and therapeutic target of hepatic fibrogenesis, which reflects prefibrotic changes, has not been established [2,3]. Therefore, development of a noninvasive biomarker for hepatic fibrogenesis, which will lead not only to establishment of a novel diagnosis useful to prevent liver fibrosis/ cirrhosis, but also to acceleration of drug discovery and development against liver fibrosis, is in high demand [3].

\section{Activation of Hepatic Stellate Cells}

Hepatic stellate cells (HSCs) play a central role in the pathogenesis of hepatic fibrosis by virtue of their ability to undergo a process termed "activation" [1,2]. During this process, HSCs transform into myofibroblast-like cells accompanying several key phenotypic changes, which collectively increase extracellular matrix accumulation [1-3]. These include (1) cellular proliferation caused by upregulation of mitogenic cytokines and their receptors; (2) morphologic changes with loss of stored 
vitamin A droplets; (3) contractility caused by increased $\alpha$ smooth muscle actin ( $\alpha$ SMA), which may constrict sinusoidal blood flow; and (4) fibrogenesis mainly caused by increased synthesis and release of collagen.

\section{TGF- $\beta$ and Its Activation Reaction}

Among many cytokines and growth factors related to fibrogenesis, the most potentand therefore the most "fibrogenic"-cytokine is the $25 \mathrm{kD}$ homodimeric cytokine, transforming growth factor (TGF)- $\beta$ [8]. The TGF- $\beta$ family is composed of three subtypes (TGF- $\beta 1$, TGF- $\beta 2$, and TGF- $\beta 3$ ), with biological properties that are nearly identical [8]. TGF- $\beta$ is produced as an inactive latent complex, in which active TGF- $\beta$ is trapped by its propeptide, latency-associated protein (LAP), and to exert its biological activities, it must be released from the complex [9]. This reaction is called activation of TGF- $\beta$ (Fig. 1). TGF- $\beta 1$ is produced as a 390 -amino-acid

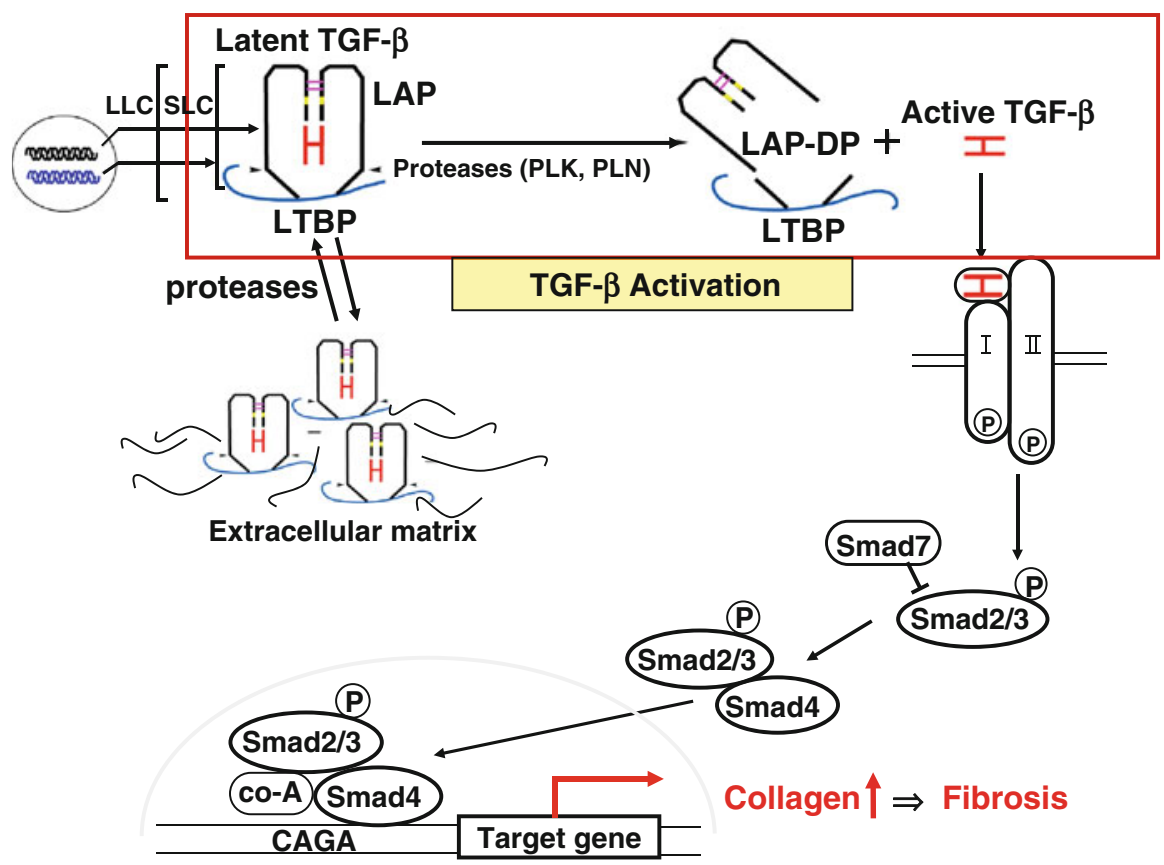

Fig. 1 TGF- $\beta$ activation and signaling pathway. TGF- $\beta$ is produced as a latent complex (LLC) composed of active TGF- $\beta$ trapped by its propeptide LAP (SLC) and a matrix protein LTBP. Upon cleavage of LAP by proteases such as PLK, active TGF- $\beta$ is released from the complex (this reaction is called TGF- $\beta$ activation) and exerts fibrogenic activity (stimulation of collagen synthesis) via binding to its receptors and Smad signaling 
precursor protein consisting of a signal peptide of 29 amino acids, an $\mathrm{N}$-terminal LAP, and a C-terminal region that becomes the active TGF- $\beta 1$ molecule, and each region is dimerized through $\mathrm{S}-\mathrm{S}$ bonds. After processing by cleavage at $\mathrm{R}^{278}-\mathrm{A}^{279}$ by a furin-like protease, the LAP still non-covalently captures the active TGF- $\beta 1$, forming small latent complex (SLC) and preventing active TGF- $\beta 1$ from binding its cognate receptors [9]. The active TGF- $\beta 1$ and the LAP homodimers are $25 \mathrm{kD}$ and $75 \mathrm{kD}$, respectively. SLC is S-S bonded to another gene product, the latent TGF- $\beta$ binding protein (LTBP), via $\mathrm{C}^{33}$ residues, forming the large latent complex (LLC). This complex can be sequestered in the ECM (Fig. 1) [10] because LTBP is a member of an ECM protein family, fibrillin [11].

Activation of latent TGF- $\beta$ is performed through different mechanisms depending on the tissue and cell types and experimental conditions, and several molecules are known to activate TGF- $\beta 1$ in animal models [12-21]. These include integrins [12-15], thrombospondin [16], and proteases, such as matrix metalloproteinases and serine proteases [17-21]. The integrin $\alpha v \beta 6$ binds to and activates latent TGF- $\beta$ and plays a role in regulating pulmonary inflammation and fibrosis as well as biliary fibrosis [12-15]. Thrombospondin 1 is another major activator of latent TGF- $\beta$, especially in the lung and pancreas, by binding to a defined site within LAP and inducing a conformational change in the latent complex [16]. In the normal liver, TGF- $\beta$ is produced and secreted from sinusoidal endothelial cells and Kupffer cells (KCs, resident macrophages in the liver) at low levels. Elevated production of TGF- $\beta$ was seen first in all cell types and then mainly in hepatocytes and HSCs after partial hepatectomy, whereas elevated production of TGF- $\beta$ was seen solely in HSCs after inflammation and fibrosis [22]. TGF- $\beta$ secreted from HPCs is entirely in the latent form, whereas TGF- $\beta$ secreted from HSCs is $50-90 \%$ in the active form [22]. Thus, HSCs are recognized as the major source of active TGF- $\beta$, namely the site of TGF- $\beta$ activation, particularly in the damaged liver [22,23].

We have addressed a potential proteolytic mechanism for latent TGF- $\beta$ activation in HSCs by surface plasmin (PLN) and plasma kallikrein (PLK) during the formation of hepatic fibrosis $[20,21]$. PLN releases latent TGF- $\beta$ from the extracellular matrix and activates it by cleaving LAP from latent TGF- $\beta$ molecules on the HSC surface $[9,20]$. Lyons et al. first reported that PLN digests LAP and activates TGF$\beta 1$ in vitro [24]. Using a protease inhibitor, camostat mesilate, we demonstrated that PLN and PLK are involved in the TGF- $\beta 1$ activation associated with liver fibrosis and impaired liver regeneration in animal models [20,21]. However, it remained to be elucidated whether PLN- and/or PLK-dependent TGF- $\beta 1$ activation also occurs during the pathogenesis of liver fibrosis in patients, as there was no good biomarker reflecting protease-dependent TGF- $\beta 1$ activation reaction. To answer this question, we determined cleavage site within LAP and made specific antibodies that recognize LAP degradation products (LAP-DPs) bearing a neo-amino or carboxyl terminus [25]. 


\section{TGF- $\beta$ LAP-DP Serves as a Surrogate Marker for Its Activation Reaction}

To identify the cleavage sites in LAP during latent TGF- $\beta 1$ activation by PLN and PLK, recombinant human LAP $\beta 1$ was digested with these proteases, the resultant fragments were separated by SDS-polyacrylamide gel electrophoresis (PAGE), and the N-terminal sequence of each LAP-DP was determined using a pulsed liquid protein sequencer Precise 494cLC, which revealed that PLN and PLK primarily cleave LAP $\beta 1$ between the $\mathrm{K}^{56}$ and $\mathrm{L}^{57}$ residues, and the $\mathrm{R}^{58}$ and $\mathrm{L}^{59}$ residues, respectively, during proteolytic activation of latent TGF- $\beta 1$ (Fig. 2) [25].

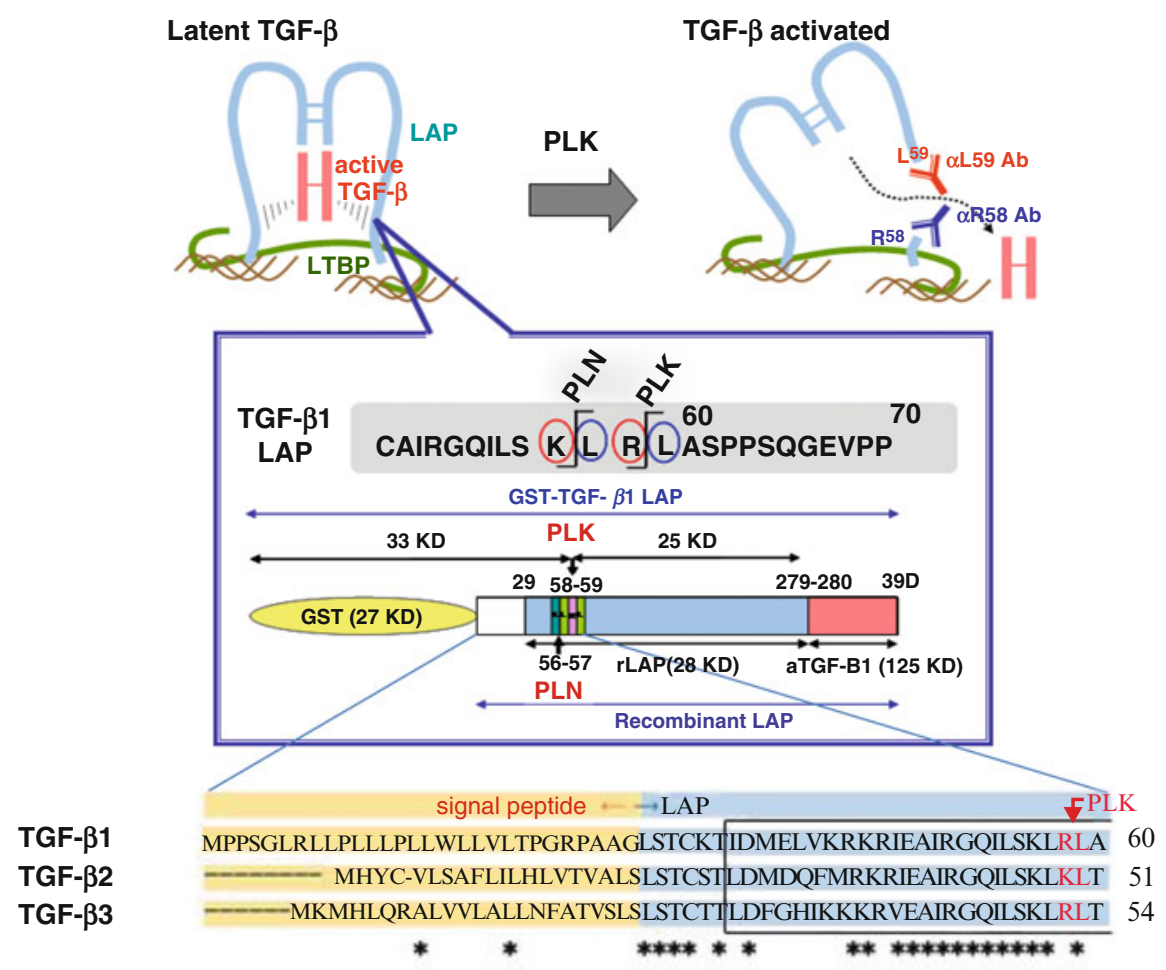

Fig. 2 Cleavage of $\mathrm{K}^{56} \mathrm{LRL}^{59}$ within LAP activates TGF- $\beta$. PLN and PLK cleave LAP between $\mathrm{K}^{56}-\mathrm{L}^{59}$ and $\mathrm{R}^{58}-\mathrm{L}^{59}$ residues, respectively, causing release of active TGF- $\beta 1$ from the latent complex. The amino acid sequences around the PLN and PLK cleavage sites are illustrated. Antibodies that specifically recognize the cutting edges of LAP-DPs were produced. The dark blue " $Y$ " labeled R58 represents antibodies recognizing the C-terminal or N-terminal side LAP-DPs, whereas the red " $Y$ " labeled L59 represents antibodies recognizing the $\mathrm{N}$-terminal or C-terminal side LAP-DPs. A comparison of amino acid sequences from the N-terminus until the PLK cleavage site among three isoforms of TGF- $\beta$ is presented at the bottom 

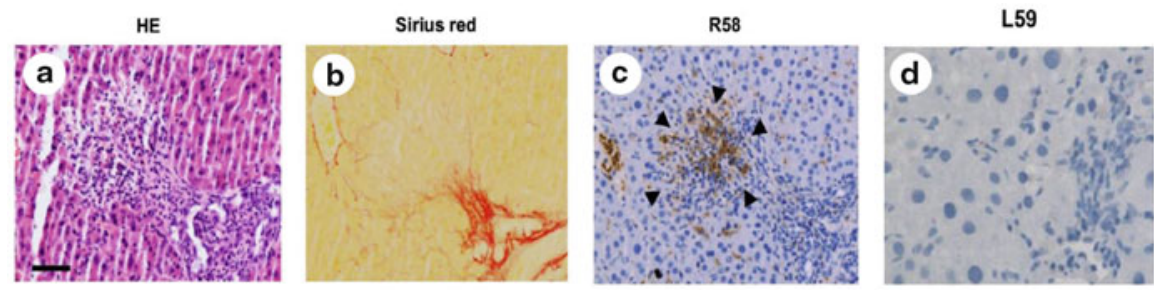

R58

aSMA
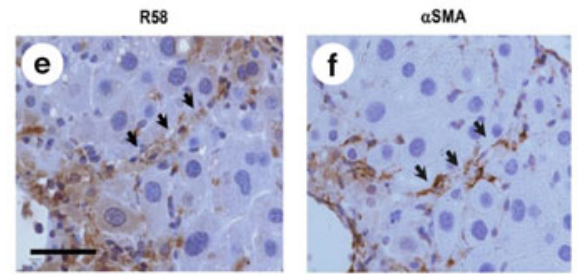

CD31

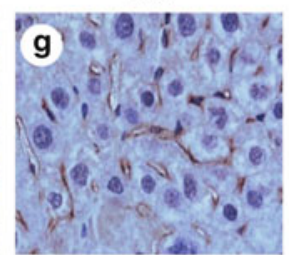

CD68

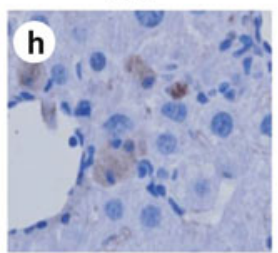

Fig. 3 Emergence of TGF- $\beta$ LAP-DPs in activated HSCs within pre-fibrotic areas in BDL models. Liver sections from BDL-operated mice were stained by HE (a) and Sirius red (b), and immunostained with R58 (c) and L59 (d) antibodies (scale bar=50 $\mu \mathrm{m}$ ), and were immunostained with R58 (e), anti- $\alpha$ SMA (f), anti-CD31 (g), and anti-CD68 (h) antibodies (scale bar=25 $\mu \mathrm{m}$ ). More detailed results are provided elsewhere [25]

To detect PLK-produced LAP-DPs, we made two monoclonal antibodies. One is the R58 antibody detecting N-terminal side LAP-DPs terminating on the $\mathrm{R}^{58}$ residue ( $\mathrm{R}^{58}$ LAP-DPs), and another is the L59 antibody detecting C-terminal side LAPDPs starting from the $\mathrm{L}^{59}$ residue ( $\mathrm{L}^{59} \mathrm{LAP}-\mathrm{DPs}$ ). We established techniques to detect each LAP-DP using these antibodies [25]. The $\mathrm{R}^{58}$ LAP-DPs remaining in tissues or cell surfaces through $\mathrm{S}-\mathrm{S}$ bonded LTBP can be detected mostly in $\alpha$ SMApositive activated stellate cells in liver tissues from both fibrotic animals and patients by immunostaining with the R58 antibody, whereas the ${ }^{59}$ LAP-DPs were not detectable by immunostaining with the L59 antibody [25]. Figure 3 shows the results obtained from bile duct ligation (BDL) mice. These mice often exhibited granulomatous lesions (panel $a$ ), in which fibroblastic cells infiltrated and started ECM production (panel $b$ ). Importantly, the $\mathrm{R}^{58}$ LAP-DPs were detected in granulomatous lesions prior to Sirius red positivity, namely before collagen accumulation (arrowheads in panel c). In contrast, L59 antibody failed to stain the $\mathrm{L}^{59}$ LAP-DPs, although various antigen unmasking procedures were treated (panel $d$ ). We found that the $\mathrm{L}^{59}$ LAP-DPs were released into the blood and could be measured by an ELISA using the L59 antibody (Hara et al., unpublished data). In panels $e-h$, nonparenchymal regions were recognized by antibody R58 (arrowheads in panel $e$ ), and mostly overlapped with $\alpha$ SMA-positive HSCs (arrowheads in panel f), but not with CD31-positive liver sinusoidal endothelial cells (panel g) nor with CD68positive KCs (hepatic macrophages) (panel $h$ ). We further found that the R58 antibody detected TGF- $\beta 1 / 3$ LAP-DPs but not TGF- $\beta 2$ LAP-DPs because of the similarity and difference of the R58 side sequence, respectively (Fig. 2). Finally, we succeeded in detecting $\mathrm{R}^{58}$ LAP-DPs in patients with chronic hepatitis $\mathrm{B}$ and $\mathrm{C}$ virus 
(HBV and $\mathrm{HCV}$, respectively) infection categorized as A1F2 and A2F2, as well as in patients with non-viral hepatitis, such as autoimmune hepatitis and non-alcoholic steatohepatitis (NASH) [25]. A specific cell shape called a "crown-like structure" (CLS) has been referred to as a biomarker for NASH in both an animal model and patients [26]. Recently, we found that $\mathrm{R}^{58}$ LAP-DPs positivity well matched the emergence of CLS [27].

These data suggest the occurrence of a PLK-dependent TGF- $\beta$ activation reaction in patients and indicate that the LAP-DP may be useful as a surrogate marker reflecting PLK-dependent TGF- $\beta 1 / 3$ activation and subsequent fibrogenesis in the fibrotic liver both in animal models and in patients.

\section{Conclusion and Future Subjects}

The most fibrogenic cytokine, TGF- $\beta$, is produced as a latent complex, in which TGF- $\beta$ is trapped by its propeptide, LAP. On the surface of activated HSCs, PLK activates TGF- $\beta$ by cleaving LAP between the $\mathrm{R}^{58}$ and $\mathrm{L}^{59}$ residues, releasing active TGF- $\beta$ from the complex. We made specific antibodies that recognize the neo-Cterminal $\left(\mathrm{R}^{58}\right)$ and $\mathrm{N}$-terminal $\left(\mathrm{L}^{59}\right)$ ends of the LAP-DP, and found that the LAP-DP may serve as a novel surrogate marker of TGF- $\beta$ activation - namely, generation of active TGF- $\beta$ - and is thereby a therapeutic marker for TGF- $\beta$-mediated liver fibrogenesis in patients [25].

Utilizing LAP-DP antibodies, we are developing techniques to visualize the fibrogenic area by positron emission tomography (PET), planning to eliminate activated HSCs with pertussis toxin, and undertaking the challenge to solve the co-crystal structure of LAP and a LAP-DP targeting inhibitor, which binds to the LAP cleavage site, thereby inhibiting TGF- $\beta$ activation and liver fibrosis in HBVinfected chimeric mice (Hara et al., unpublished data). The effectiveness of an inhibitor against the TGF- $\beta$ activation reaction has been reported in the integrinmediated activation of TGF- $\beta[3,15,28]$. LAP-DP is also used to monitor the effects of anti-fibrogenic factors or compounds for discovery of a novel anti-fibrosis drug. For example, we recently found that HCV NS3 protease mimics TGF- $\beta 2$ and enhances liver fibrosis via binding to and activation of the TGF- $\beta$ type I receptor, and that an anti-NS3 antibody raised against the predicted binding sites attenuates liver fibrosis in HCV-infected chimeric mice [29]. In this study, R58 LAP-DP staining nicely showed the anti-fibrogenic potentials of the anti-NS3 antibody.

The technique developed accelerates drug discovery targeting TGF- $\beta$-dependent fibrogenesis in patients suffering from chronic hepatitis.

Acknowledgments This work was supported partly by the Program for Promotion of Fundamental Studies in Health Science of the National Institute of Biomedical Innovation (NIBL) and a grant from the Uehara Memorial Foundation, Japan (to S.K.), Research on the Innovative Development and the Practical Application of New Drugs for Hepatitis B (Principal investigator: Soichi Kojima; H24-B Drug Discovery-Hepatitis-General-003), provided by the Ministry of Health, Labor and Welfare of Japan. 
Open Access This chapter is distributed under the terms of the Creative Commons Attribution Noncommercial License, which permits any noncommercial use, distribution, and reproduction in any medium, provided the original author(s) and source are credited.

\section{References}

1. Bataller R, Brenner DA (2005) Liver fibrosis. J Clin Invest 115:209-218

2. Friedman SL (2008) Mechanism of hepatic fibrogenesis. Gastroenterology 134:1655-1669

3. Schuppan D, Kim YO (2013) Evolving therapies for liver fibrosis. J Clin Invest 123:1887-1901

4. Kuno A, Ikehara Y, Tanaka Y, Ito K, Matsuda A, Sekiya S, Hige S, Sakamoto M, Kage M, Mizokami M, Narimatsu H (2013) A serum "sweet-doughnut" protein facilitates fibrosis evaluation and therapy assessment in patients with viral hepatitis. Sci Rep 3:1065

5. Ikeda K, Izumi N, Tanaka E, Yotsuyanagi H, Takahashi Y, Fukushima J, Kondo F, Fukusato T, Koike K, Hayashi N, Kumada H (2013) Fibrosis score consisting of four serum markers successfully predicts pathological fibrotic stages of chronic hepatitis B. Hepatol Res 43:596-604

6. Fallatah HI (2014) Noninvasive biomarkers of liver fibrosis: an overview. Adv Hepatol. Article ID 357287

7. Kazankov K, Barrera F, Møller HJ, Bibby BM, Vilstrup H, George J, Grønbaek H (2014) Soluble CD163, a macrophage activation marker, is independently associated with fibrosis in patients with chronic viral hepatitis B and C. Hepatology 60:521-530

8. Dooley S, ten Dijke P (2012) TGF- $\beta$ in progression of liver disease. Cell Tissue Res 347:245-256

9. Dabovic B, Rifkin DB (2008) TGF- $\beta$ bioavailability: latency, targeting, and activation. In: Derynck R, Miyazono K (eds) The TGF- $\beta$ family. Cold Spring Harbor Laboratory Press, New York, pp 179-202

10. Breitkof K, Lahme B, Tag CG, Gressner AM (2001) Expression and matrix deposition of latent TGF- $\beta$ binding proteins in normal and fibrotic rat liver and transdifferentiating hepatic stellate cells in culture. Hepatology 33:387-396

11. Zilberberg L, Todorovic V, Dabovic B, Horiguchi M, Couroussé T, Sakai LY, Rifkin DB (2012) Specificity of latent TGF- $\beta$ binding protein (LTBP) incorporation into matrix: role of fibrillins and fibronectin. J Cell Physiol 227:3828-3836

12. Margadant $C$, Sonnenberg A (2010) Integrin-TGF- $\beta$ crosstalk in fibrosis, cancer and wound healing. EMBO Rep 11:97-105

13. Shi M, Zhu J, Wang R, Chen X, Mi L, Walz T, Springer TA (2011) Latent TGF- $\beta$ structure and activation. Nature 474:343-349

14. Henderson NC, Sheppard D (2012) Integrin-mediated regulation of TGF $\beta$ in fibrosis. Biochim Biophys Acta 1832:891-896

15. Patsenker E, Popov Y, Stickel F, Jonczyk A, Goodman SL, Schuppan D (2008) Inhibition of integrin $\alpha v \beta 6$ on cholangiocytes blocks transforming growth factor- $\beta$ activation and retards biliary fibrosis progression. Gastroenterology 135:660-670

16. Ribeiro SM, Poczatek M, Schultz-Cherry S, Villain M, Murphy-Ullrich JE (1999) The activation sequence of thrombospondin-1 interacts with the latency-associated peptide to regulate activation of latent transforming growth factor- $\beta$. J Biol Chem 274:13586-13593

17. Jenkins $G$ (2008) The role of proteases in transforming growth factor- $\beta$ activation. Int $J$ Biochem Cell Biol 40:1068-1078

18. Du X, Shimizu A, Masuda Y, Kuwahara N, Arai T, Kataoka M, Uchiyama M, Kaneko T, Akimoto T, Iino Y, Fukuda Y (2012) Involvement of matrix metalloprotease-2 in the development of renal interstitial fibrosis in mouse obstruction nephropathy. Lab Invest 92:1149-1160 
19. Lyons RM, Gentry LE, Purchio AF, Moses HL (1990) Mechanism of activation of latent recombinant transforming growth factor beta 1 by plasmin. J Cell Biol 110:1361-1367

20. Okuno M, Akita K, Moriwaki H, Kawada N, Ikeda K, Kaneda K, Suzuki Y, Kojima S (2001) Prevention of rat fibrosis by protease inhibitor, Camostat Mesilate, via reduced generation of active TGF- $\beta$. Gastroenterology 120:1784-1800

21. Akita K, Okuno M, Enya M, Imai S, Moriwaki H, Kawada N, Suzuki Y, Kojima S (2002) Impaired liver regeneration in mice by lipopolysaccharide via TNF- $\alpha /$ kallikrein-mediated activation of latent TGF- $\beta$. Gastroenterology 123:352-364

22. Bissell DM, Wang SS, Jarnagin WR, Roll FJ (1995) Cell-specific expression of transforming growth factor- $\beta$ in rat liver. Evidence for autocrine regulation of hepatocyte proliferation. $\mathbf{J}$ Clin Invest 96:447-455

23. Friedman SL (1993) The cellular basis of hepatic fibrosis. N Engl J Med 328:1828-1835

24. Lyons RM, Keski-Oja J, Moses HL (1988) Proteolytic activation of latent transforming growth factor- $\beta$ from fibroblast-conditioned medium. J Cell Biol 106:1659-1665

25. Hara M, Kirita A, Kondo W, Matsuura T, Nagatsuma K, Dohmae N, Ogawa S, Imajoh-Ohmi S, Friedman SL, Rifkin DB, Kojima S (2014) LAP degradation product reflects plasma kallikrein-dependent TGF- $\beta$ activation in patients with hepatic fibrosis. Springerplus 3:221

26. Itoh M, Kato H, Suganami T, Konuma K, Marumoto Y, Terai S, Sakugawa H, Kanai S, Hamaguchi M, Fukaishi T, Aoe S, Akiyoshi K, Komohara Y, Takeya M, Sakaida I, Ogawa Y (2013) Hepatic crown-like structure: a unique histological feature in non-alcoholic steatohepatitis in mice and humans. PLoS One 8, e82163

27. Konuma K, Itoh M, Suganami T, Kanai S, Nakagawa N, Sakai T, Kawano H, Hara M, Kojima S, Izumi Y, Ogawa Y (2015) Eicosapentaenoic acid ameliorates non-alcoholic steatohepatitis in a novel mouse model using Melanocortin-4 receptor-deficient mice. PlosOne 10, e0121528

28. Allison M (2012) Stromedix acquisition signals growing interest in fibrosis. Nat Biotechnol 30:375-376

29. Sakata K, Hara M, Terada T, Watanabe N, Takaya D, Yaguchi S, Matsumoto T, Matsuura T, Shirouzu M, Yokoyama S, Yamaguchi T, Miyazawa K, Aizaki H, Suzuki T, Wakita T, Imoto M, Kojima S (2013) HCV NS3 protease enhances liver fibrosis via binding to and activating TGF- $\beta$ type I receptor. Sci Rep 3:3243 